March - 2007

\title{
The Practice of a Quality Assurance System in Open and Distance Learning: A case study at Universitas Terbuka Indonesia (The Indonesia Open University)
}

\author{
Tian Belawati and Amin Zuhairi \\ Universitas Terbuka, Indonesia
}

\begin{abstract}
Quality assurance for distance higher education is one of the main concerns among institutions and stakeholders today. This paper examines the experiences of Universitas Terbuka (UT), which has initiated and implemented an innovative strategy of quality assurance (QA) for continuous improvement. The credo of the UT quality assurance system is "We write what we do. We do what we write. We check. We improve continuously!" Implementing a quality management system at the UT, a mega-university with a student body of more than a quarter of a million and which involved a network of participating institutions and regional centres, was a formidable task to accomplish. To achieve its lofty goal, UT adopted and contextualised the draft of the Asian Association of Open Universities (AAOU) QA Framework to launch its own quality assurance program. This has taken a great deal of commitment and participation of all staff involved. QA at the UT required systematic and step-by-step processes, including development of the QA framework and job manuals, raising awareness and commitment amongst all staff involved, internal assessment, and integration of QA programs into the university's annual action plans, external assessment and benchmarking. This paper concludes that quality assurance must be developed as institutional policy and strategy for continuous improvement.
\end{abstract}

Keywords: Quality assurance; continuous improvement; quality management; distance higher education; open university

\section{Introduction}

Over the past few years, there has been significant growth of quality assurance (QA) activities aimed towards improving higher education on institutional, national, regional, and global levels. Public and institutional stakeholders seeking accountability in higher education have encouraged governments to establish national quality assurance and accreditation agencies. Agencies, such as European Network of Quality Assurance (ENQA), International Network of Quality Assurance Agencies for Higher Education (INQAAHE), and the United Nations Educational, Scientific and Cultural Organization (UNESCO), typically work together and share information about quality standards, benchmarks and best practices. A number of terminologies have been developed and used to refer to similar ideas of improving the quality of higher education, such as quality 
assurance, quality assessment, quality improvement, and quality development (Harman, 2000; Brennan \& Shah, 2000; Hopkin \& Lee, 2001; Gosling \& D'Andrea, 2001). However, while the definition of quality assurance may differ, all quality assurance terminology shares a common purpose in ensuring that students receive a high quality and relevant education and awarded credentials that are widely recognized by governments and employers.

Quality assurance has been defined as "systematic management and assessment procedures adopted by higher education institutions and systems in order to monitor performance against objectives, and to ensure achievement of quality outputs and quality improvements" (Harman, 2000, p. 1). Quality assurance facilitates recognition of the standards of awards, serves public accountability purposes, helps inform student choice, contributes to improved teaching learning and administrative processes, and helps disseminate best practices with the goal of leading to overall improvement of higher education systems. Setting common standards and evaluation criteria, however, must take into account diversity and plurality of higher education within national, as well as regional systems. Higher education institutions are challenged to develop new visions, new forms of collaboration across institutions and nations (Harman, 2000). Brennan and Shah (2000) use the term 'quality assessment,' whose common methods and elements include 1) a national coordinating body; 2) institutional self-evaluation; 3) external evaluation by academic peers; and 4) published reports. They further identify four main types of "quality values" they determine to underpin different approaches to quality assurance: academic, managerial, pedagogic, and employment focus.

In general, the term QA refers to a process of defining and fulfilling a set of quality standards consistently and continuously with the goal of satisfying all consumers, producers, and the other stakeholders. In engineering and manufacturing, for example, 'quality control' or 'quality assurance' is viewed as a set of measures undertaken to ensure that defective products or services are not made - typically under the credo 'do it right the first time' - and that the design meets the product or service meets predetermined performance requirements. It includes the regulation of the quality of raw materials, assemblies, products and components; services related to production; and management, production, and inspection processes. QA programs typically include peer or utilization review procedures to remedy any identified deficiencies in quality (Wikipedia, n.d.).

In the context of education, 'quality' has been placed high on the agenda of educational leaders, policy makers, and practitioners, and is in line with consumers' ever increasing demand for quality education. In many countries, stakeholders have been placing high expectations on their educational systems, compelling institutions to produce higher quality products, services, processes, and by extension, students and graduates. Governments have also been seeking increased levels of accountability from their publicly funded educational institutions. Faced with the globalization of the world economy, coupled with associated challenges of producing highcaliber human resources needed to effectively participate in the global economy, national stakeholders have voiced serious concerns about the 'quality' of their educational provisions to ensure their competitiveness. Thus, it is clearly imperative that educational institutions continuously improve the quality of their educational provision (UT, 2002).

\section{Quality Assurance in Open and Distance Learning}

Quality has always been an issue in distance education (DE) and distance learning (DL). Since DE's inception and subsequent widespread diffusion, DE has been increasing access to education, a reality that has compelled many countries to adopt DE as part of their educational system (Garrison, 1993). Further, this paradigm of 'access to education' is in line with the belief of 
student autonomy and independence, as students studying at a distance often do so alone (Moore, 1993).

As societies evolve from the post-industrial era to the information age, DE has also been similarly evolving. As a result, concerns about the quality of DE provisions have been of central importance and subject to study. For instance, interactive communication between and among students and tutors is now being emphasized (Belawati, 1999). It is within this 'access to education' paradigm that 'quality assurance' has become one of the fundamental aspects in planning and managing open and distance learning (ODL) provisions.

Since the 1990s, quality assurance in distance and higher education has gained serious attention by institutions, stakeholders, and scholars. In response to QA line of inquiry, institutions have begun to re-define and re-orient their institutional missions and strategic visions to incorporate and address quality issues. QA has now reached an important turning point and is influencing DE institution's management strategies and cultures. Numerous reports have been published to share ideas, experiences, and articulate the 'how and how not to' and 'best practices' of QA implementation in DE contexts from around the world (Deshpande \& Mugridge, 1994; Tait, 1997).

Stakeholders interested in ODL have become increasingly interested in quality assurance issues. Learners are demanding better quality educational services and provisions. This means ODL providers must pay close attention to quality in terms of products, processes, production, delivery systems, and philosophy (COL, 1997). The 'total quality approach,' which covers not only products but services and processes as well, is a very useful methodology that holistically examines the process of ODL as an integrated whole (Zuhairi, Purwanto \& Isman, 2002).

Quality improvement becomes imperative for ODL providers, and governments have established quality agencies to improve the quality of educational practice. Pressures for quality improvement have emerged from both internal and external parties. Internally, ODL institutions are being challenged to undertake continuous improvement from within. Externally, stakeholders (i.e., users, consumers, educational funders) are persistently questioning the quality, accountability, effectiveness and efficiency of educational endeavors in which they have interest. Moreover, for many ODL institutions funding and student enrollment levels depend on quality of their bottom line performance and the quality of the services they offer.

Despite the importance of the process component as a whole, 'quality' in ODL tends to viewed in terms of 'materials' produced. Judging the quality of ODL products is relatively easy, however. The course materials, which are often the primary means of engaging learners, are tangible and open to scrutiny by students and other interested parties. Indeed, it is much easier to judge the quality of a tangible product of say, a course syllabus and curriculum, than of less tangible aspects such as learning process, teamwork, or management (COL, 1997). Clearly, quality in ODL covers a number of aspects, which along with the physical products, includes pedagogical processes, production and delivery systems, and philosophy (COL, 1997). Quality of products includes course materials, number of graduates, examination pass rates, admission in further studies, and so forth. Quality of processes covers areas such as learning and teaching processes, advising students, coordinating external course and test item writers, networking with regional offices, managing student information. Quality of production and delivery systems includes course production, print and multimedia production, test item production, scheduling, warehousing and stock control, getting materials to students, and broadcast transmissions. Quality 
of philosophy covers such things as ODL vision, mission and policy statements, institutional culture, governance, corporate culture, and public image (COL, 1997).

In terms of products, the quality of ODL varies from one institution to another, depending on priorities, resources, size, and the student body of which it aims to serve (COL, 1997). For instance, ODL institutions in developed countries typically use ICT-based courses, while institutions in developing countries use printed materials as its primary medium of instructional delivery. The use of ICT in ODL in the developing country such as Indonesia is still at experimental stages, and even though many institutions are ready to experiment with modern ICT-based courses, access and participation by students is still relatively low (Belawati, 2005). It is the challenge for institutions in the developing country such as Indonesia to socialize and educate students, educators and the society in using ICT facilities for ODL enterprise (Belawati, 2005).

Quality of processes is more difficult to address than products. Various kinds of learning supports may be provided by institutions like tutorial services, organized study groups, library access, and access to learning resources (COL, 1997). Indeed, most ODL students are at liberty to decide for themselves whether or not to use learning resource facilities (COL, 1997) and in some cases, students cannot access learner support facilities - i.e., living far from learner support facilities (Fozdar, Kumar \& Kanan, 2006). The challenge for ODL institution, therefore, is not only to ensure learner support that is both accessible and relevant, but also to encourage students to participate in and use of support systems that ensure quality-learning. Management and decisionmaking processes are similarly difficult to assess. Indeed, it takes some time to observe how the quality of 'decision-making' influences a given institution (COL, 1997).

In terms of production and delivery system, ODL may be likened to industrial management (Peters, 1983). Management is crucial in ODL, as management activities follow assembly-line procedures and some jobs require craftsmanship. Deadlines and schedules must be met. What goes wrong in one activity can have a domino effect on subsequent activities, oftentimes with devastating consequences. For instance, delays in meeting course development deadlines can result in delays in production, printing, dispatching, and even in whether or not students receive their learning materials on time. In extreme cases, students examination schedules can be postponed, simply because they did not receive their learning materials in time. Producing learning materials - including tutorial services - requires quality professionalism (UT, 2002).

In terms of philosophy, the institution's vision, mission, and policy documents are often wellstated and tend to be widely circulated among staff. The problem, however, is 'how' staff actually understands the meaning of these documents (Daft, 2006). The challenge for ODL leaders therefore, is to engineer organizational change in such a manner that staff members focus their time, energies, and priorities on achieving institutional goals and missions. Consultation and communication between institutional leaders and staff is necessary to socialize and internalize these ideals, making them part of the organizational culture based on QA principles. Implementation of the institutional missions, polices, and strategies requires constant follow-up and guidance from the top level leaders (Daft, 2006).

ODL in higher education institutions is under increasing pressure to meet students' demand for flexibility, as students have increasingly diverse background and needs. To meet this challenge, innovation in is essential. Innovation in ODL assumes that new techniques will help individual institutions achieve their aims in terms of concrete access, cost, quality, and flexibility (Daniel, 1999). In this context, technology becomes a vital tool in ODL. For technology-based 
universities, particularly open universities, the quality of teaching and learning is of critical importance, as ODL materials are open to public access and scrutiny, and when the use of information and communication technology is involved, such access can often become global (Bates, 2000). Components of quality in technology-based educational materials include content, media production, instructional design, and delivery and student support (Bates, 2000).

QA can be adopted as an effective method and tool to respond to the challenge of quality in ODL. QA is not an effort to create quality, but rather a systematic and comprehensive effort to improve quality. QA, therefore, is not a means to achieve particular target and develop procedures, but rather a continuous process of improvement. QA is based on the assumption that quality can be improved continuously. Systems and procedures that are developed for this purpose ensure that staff continuously and critically question the quality of ODL products and processes, and continuously attempt to improve it. Because QA is inspired by the business practice, it uses the language commonly applied in business, such as customer, service, product, and efficiency. Traditionally, educational institutions consider such an approach as inappropriate; however, escalating pressures from all stakeholder groups for greater accountability requires ODL institutions to have quality self-assessment. ODL systems operate like a service organization premised on industry-like operations, such as design, development, production, and distribution of multimedia learning materials.

Implementing QA principles in a DE institution is a monumental task. It takes a great deal of effort, patience, socialization and training to ensure that innovation is a productive effort. People in organizations undergoing change will talk about quality, but may not know exactly what 'quality' means, specifically how to initiate, provide, and improve upon quality processes, products, and services continuously. Changing an organization's mindset is one of the biggest tasks when undergoing 'innovation'. Such change requires a great deal of courage and commitment of the top leaders of an institution (Daft, 2006). Implementation of QA implies change of work culture of staff at all levels. Everyone in the organization must think about - and more importantly, do something - to effect quality improvements in every step of their work activities. In theory, drafting organizational change and improvement could be easy (Daft, 2006). In practice, however, leading people towards change is a formidable task. People tend to maintain status quo, and resist new ideas, even if these ideas are to improve their professional practice (Daft, 2006; D'Aprix, 1995).

Realizing that change is difficult to achieve, coupled with the need to increase the accountability of their educational institutions, the Indonesian Ministry of National Education states that every higher education institution in Indonesia must have a QA system in place, one which will ensure the realization of Indonesia's vision in satisfying the stakeholders' social, industrial, and professional needs. To ensure the application of any QA system within universities, the Ministry of National Education through its Directorate General of Higher Education has generated institutional reports examining the implementation of QA, which is one of the core requirements for obtaining the government-funding through both competitive and devoted funding schemes. Even without this external pressure, Universitas Terbuka (UT) has been committed to and implementing an internal QA system to assure its accountability to its stakeholders.

\section{About the Universitas Terbuka}

Indonesia embraced DE in 1955 with the establishment of a correspondence diploma program aimed to upgrade teachers. It was not until 1981, however, when two 'crash' DE projects were developed to provide in-service training to secondary and tertiary level teachers to enhance their 
teaching skills, and help Indonesia meet the demand for additional teachers. Indeed, teachers who required upgrading could only upgrade their skills via $\mathrm{DE}$, since regular face-to-face training was too expensive and replacing teachers for further training was difficult. It was these programs which later formed a sizable part of Universitas Terbuka (Indonesia Open University) in 1984.

UT currently serves over 320,000 students nationwide. UT is supported by a strong centralized management system with its Head Office (HO) located in the capital city of Jakarta and 37 Regional Offices (ROs) throughout the country. Although these offices are located in or very near relatively big cities, they oftentimes do not have the appropriate infrastructure for accessing electronic communication. Despite recent efforts to enhance the use of ICT, communication between UT's HO and its ROs still rely heavily on mail and courier services, telephone, and/ or facsimile. The use of ICT-based communication channels, such as e-mail, has only been available since 2004.

UT offers over 1000 courses delivered through 34 Study Programs, under four faculties: Faculty of Economics and Developmental Studies (FEKON), the Faculty of Social and Political Sciences (FISIP), the Faculty of Mathematics and Natural Sciences (FMIPA), and the Faculty of Teacher Training and Educational Studies (FKIP). The Faculty of Education offers only in-service training programs for practicing primary and secondary school teachers, while the other three faculties are open for high-school graduates and working adults.

\section{Establishment of a QA Centre and Adoption of a QA Framework}

The changing paradigm in higher education management, including higher education at a distance, has triggered UT to implement a quality assurance system. Historically, 'quality' was one of the key agendas of the Indonesian Government and its cadre of higher education institutions,. Nonetheless, many institutions - UT included - faced constraints and hurdles that made it very hard to put the idea of 'quality' into a concrete practice. Efforts to improve the quality of DE services already existed in UT albeit very broadly. It was only in 2001 when UT developed its 2001-2005 Operational Plan, that 'quality' was explicitly focused on three core areas: 1) academic quality; 2) student participation; and 3) internal management (UT, 2001).

Based on that 2001-2005 Operational Plan, concrete action was taken in the formal establishment of a Quality Assurance System Committee in October 2001. This committee charged with developing UT's quality policy manual, comprised 10 people under direct supervision by UT's Rector and Vice Rectors. Their first assignment was developing a framework for UT's quality assurance system. Being one of the founding fathers of the Asian Association of Open University (AAOU), the Committee believed that the AAOU Quality Assurance Framework (still in draft at that time) should be referred to, and adopted at, UT. Guided by the AAOU framework, the Committee formulated the university's QA policies in consultation with the university's high officials, followed by in-depth discussions with UT staff in various units. Eventually all involved agreed on the policies stated in Sistem Jaminan Kualitas (Quality Assurance System) Universitas Terbuka (UT, 2002) abbreviated here as SIMINTAS.

UT's quality policy manual was further disseminated at the annual National Coordination Meeting, held at UT's HO in April 2002. One major outcome of this meeting was the development of definitions for 'quality self-assessment' and recommendations for improvement. UT followed-up by writing quality assurance manuals that systematically documented UT's operational activities and procedures, and put in place protocols to continuously improve and consistently apply the documented procedures in UT's daily work activities. Numerous small 
teams, comprising over 200 academic and administrative staff, worked intensively and cooperatively to produce UT's quality assurance manuals and pilot and implement the procedures. The significant outcome of this activity was the development of UT as a 'learning organization' wherein people readily learn the best practices of others (Daft, 2006).

During the follow-up National Coordination Meeting in March 2003, the implementation of SIMINTAS was formalized under the auspices of the Rector's Letter of Decision on the Use of QA Manuals. In 2003, 113 QA manuals were produced documenting UT operational activities and were ready for use to guide UT's activities and operations. On July 21, 2003, the Quality Assurance System Committee was formalized and converted into the QA Centre (known as the Pusat Jaminan Kualitas abbreviated here as PUSMINTAS). Beginning in 2004, UT entered the New Year with "the Spirit of Quality Assurance System" called the "Gelora SIMINTAS" in which UT transformed itself into becoming a full-fledged learning organization.

The year 2004 was a significant milestone for UT, as that is when UT finally put its words into action. 2004 saw UT using its QA manuals consistently; it saw UT implementing its QA system using tangible annual action plans to support continuous improvement; it saw UT participating, supervising, and motivating its staff to accomplish sets of specified targets; and saw UT establishing an organizational culture focused on quality and efficiency as documented in its QA manuals.

As in any organizational change initiative, however, some staff members reacted unfavourably and agitated to retain their timeworn, conventional work styles. Quality improvement, on the other hand, not only necessitates significant effort, commitment, and investment in terms of time, resources and cost, it requires all staff members to question and challenge all they take for granted. Indeed, QA requires significant and active participation from all people within the institution. This not only takes clear direction from leadership, it takes solid, ongoing commitment from all levels to improve UT's quality continuously.

\section{The Steps of QA System Implementation}

As stated previously, UT adopted the Asian Association of Open Universities (AAOU) Quality Assurance (QA) Framework, drafted to assist AAOU Member institutions, in which UT was but one of many founding members. To contextualize AAOU framework, UT modified the AAOU best practices and developed quality indicators to address its unique institutional needs and relevance within the Indonesian higher educational context. UT's implementation of AAOU framework used the following five steps:

1. Development of QA policy manual

2. Self-evaluation and priority-setting for quality improvement

3. Development of the QA job manuals

4. Implementation and revision of the QA job manuals

5. Continuous evaluation of QA implementation

\section{Development of $Q A$ policy manual}

Modifying AAOU QA framework as a guide, the PUSMINTAS Team formulated the university's QA policies in the form of 'best practices.' These policies, later known as the QA Policy Manual, 
comprise 107 'best practices' under nine main components, and reflect the UT's comprehensive needs to operate quality DE programs:

1. Policy and planning (7 best practices)

2. Human resource recruitment and development (9 best practices)

3. Management and administration (21 best practices)

4. Learners (10 best practices)

5. Program design and development (6 best practices)

6. Course design and development (14 best practices)

7. Learning supports (18 best practices)

8. Assessment of student learning (15 best practices)

9. Media for learning ( 7 best practices)

\section{Self-evaluation and priority setting for quality improvement}

In order for UT to understand the existing 'quality,' it is important to self-evaluate perceived notions of 'quality' in each sub-process within the university's larger operations versus best practices as formulated and articulated in the QA Policy Manual. To effect QA implementation, therefore, the 'best practices' contained in the QA Policy Manual were converted into a selfevaluation instrument using quality indicators and 1-4 Likert-type scales to assess individual best practice statements.

The quality self-evaluation was carried out using a consensus approach and conducted step-bystep, with 'self-evaluation' starting at the lowest unit level (e.g., academic department) moving higher up the university hierarchy. At each level, the unit was asked to honestly and consistently self-evaluate their processes on each quality indicator. This level of 'self assessment' was blameless, meaning it was not intended to 'point fingers' but instead to realistically identify the strengths, weaknesses, achievements, or mistakes of any particular unit. Results of quality selfassessment reported both low and high-perceived quality levels, as measured on 'best practices' in the QA Policy Manual.

UT's self-evaluation activity was administered twice, first in 2002 and then again 2005, using the same instrument. Results of UT's self-evaluation have been cautiously encouraging. While there was an increase in the average score over time for all 107 best practices in the survey instrument, ranging from 2.46 in 2002 to 3.83 in 2005 (an increase of 1.37), many felt that the increase should have been higher. The results of UT's self-evaluation survey was discussed at length and, upon closer examination, it was generally felt the lower-rate of change was due to the fact that staff expected to achieved more than was possible, and not because of lower levels of actual achievement. When viewed in this light, the findings show that 'quality' is on everyone's mind.

\section{Development of the QA Job Manuals}

The self-evaluation instrument also gathered data on 'shared opinions' about the priority for improvement. Based on both the 'perceived importance' and 'perceived quality' of each aspect, priorities were determined. In order for UT to assess its practices continuously, it became clear that all systems, mechanisms, and procedures needed to be documented. Thus, UT's first priority was to develop in-depth Job Manuals. 
UT's QA Job Manuals were articulated as reference standards; they contain well-defined and clearly stated systems and procedures, records of activities, and work instructions to guide staff in their daily activities. Put simply, UT's QA Job Manuals were developed to support continuous improvement throughout the UT organization. The QA Job Manuals describe UT's work-flow and activities in detail along with performance standards, expected output, and needed resources and competencies to perform each job.

The QA Job Manuals define tasks and show the interrelationship between individual units and other units charged with performing specific activities. The outcome was a systematic process map of individual activities and their interrelationships with various other activities. The result was a visual flowchart with clear descriptions of each activity and a visual relationship to other activities. The procedures described in QA Job Manuals show in detail the stages of each activity and organised systematically to build a vision of what the whole system should look like and how it should optimally operate. In sum, UT's QA Job Manuals contain project objectives, scope, definition, reference, requirement, related unit(s), and detailed description about various activities.

More significantly, the QA Job Manuals were developed by the users themselves in that they were formulated and written by hundreds of UT staff drawn from various units within UT, and broken out into small groups. Put simply, the QA Job Manuals detail real jobs and provide guidelines for activities. Those charged with writing the manual determined the scope of the manual; developed the manual's outline; wrote the first draft; reviewed and revised subsequent drafts; and finally, implemented the manual. Each unit in UT has specific working procedures and as such, the number of OA Job Manuals developed has increased to address UT's organizational needs. As of December 2005, UT has developed 198 job manuals to guide various tasks (See Appendix 1).

\section{Implementation and revision of the QA Job Manuals}

The next critical phase is implementing the OA Job Manuals. First, everyone needs to know where they are going, and a rough 'roadmap' detailing how they should get there. To help employees navigate the roadmap to UT's collective future, institutional leaders clearly articulated their vision of UT's future. They shared their vision of UT's future, repeated from time-to-time to ensure everyone is on the same page, and that everyone understands what is expected of them in performing their daily tasks. These expectations are articulated in the OA Job Manuals.

It is important to note that while the OA Job Manuals document existing procedures and practices, all staff members were asked to reflect critically upon their work activities and strive to incorporate new quality standards. Staff were also asked to evaluate to whether or not the formally stated performance standards and indicators as written in the OA Job Manuals were, in fact, achievable given their actual work experiences. This reflective activity helped UT's staff members to identify roadblocks challenging their progress towards 'quality.'

Throughout, UT's senior leadership was very active setting examples for staff, providing learning and training opportunities, and providing guidance and supervision where and when needed. The goal of such deep 'self-examination' ultimately results in staff challenging and changing outdated work practices that would otherwise likely remain the status quo. 


\section{Continuous evaluation of QA implementation}

Effective implementation of QA requires significant change in the collective mindset-set and work culture of the institution. QA requires everyone within the institution to walk the talk by appreciating, respecting, and applying 'quality' everyday. The challenge for leadership is to carefully manage the innovations and changes taking place, and transform existing culture to one that is 100 percent supportive of QA as a daily work goal. Implementing QA in a large institution, such as UT, necessitates constant commitment, strong perseverance, solid esprit de corps, to ensure it can have the greatest and most positive impact both internally and externally. This takes highly visible and vocal leaders committed to providing and instilling QA in all staff members.

The role of human resources is significant in implementing QA. Simply put, people make things happen. Units and individuals meeting or exceeding high-performance standards need to be fairly assessed and rewarded for their efforts. To meet this objective, UT developed a fair performance appraisal system comprised of 1) clearly defined job descriptions; 2) clearly defined performance standards; 3) fair performance assessment procedures; 4) an equitable appeal process; 5) an incentive system tied to performance; and 6) confidential feedback mechanisms. In other words, UT is seeking to reward its quality performers while at the same time seeking to identify underperformers and offer assistance to help them reach minimum levels of quality performance. In sum, UT's goal is provide the means to allow its people to improve the university's overall performance and support its efforts in continuous quality improvement.

Since first introducing QA is 2003, UT has been steadily evolving into a true 'learning organization' (Daft, 2006). Critical evaluation and self-reflection - primarily achieved during the drafting the OA Job Manuals - has motivated UT staff to work more effectively and efficiency. In fact, many UT staff members are now obsessed with performance, improvement, and quality. This is evident in UT's QA Job Manuals, which have been revised three times in less than three years. With each revision, one can read more and more credos such as "quality begins with us." Indeed, strong commitment from UT's leadership at all levels has made everyone working for UT think constructively and act to produce highest-quality ODL products needed to satisfy ever increasing consumer demand.

\section{External Assessment and Accreditation}

Quality is a perception, which must be verified. Indeed, it is easy to talk about QA, but it is much harder to put words into action. This means 'perceptions' of QA need to be validated by external auditors. External audits are not only needed to assure external stakeholders that UT is performing well, but also provide an valuable feedback to UT staff on whether or not they are, in reality, achieving UT's 'quality' benchmarks.

External quality assessments force institutions into proving the 'soundness' their QA systems. Such audits typically review documented procedures and physical products versus actual performance. To gain this valuable outside perspective, UT invites quality assessors from different outside agencies to assess its overall performance. Such agencies include the International Council for Open and Distance Education (ICDE); the International Standards Agency (ISA); the International Organization for Standardisation (ISO); and the National Accreditation Board for Indonesian Higher Education (BAN-PT). 
ICDE is the largest DE membership organization. ICDE has been actively engaged in defining QA and certification of trans-national educational providers for many decades, especially of ODL provisions worldwide. The ICDE-ISA, an open and distance education standards agency, was established as a global actor in the field of quality assessment. ICDE-ISA's mandate is to promote public confidence in ODL, in its standards, in its awards, in its quality. As written in its official publication (ICDE, n.d.), ISA's audits does not involve academic standards or qualifications simply because no universally agreed upon international standards for qualifications currently exists. Moreover, curriculum and academic content are regulated by the country or region of origin and outside legislative purview of international agencies. In short, ICDE-ISA assumes that institutions will be operating within their overall national context and subject to their own national legislation and guidelines. As such, ISA audit is more concerned with auditing on broader concepts, such as an institution's responsibility to its ODL students. Put simply, ICDEISA's audit places emphasis on students - specifically, the quality of the information they receive, the means by which ODL is facilitated and supported to their best benefit, and basic expectations of the what they might reasonably expect to achieve. In 2005, ISA's award of Certificate of Quality and International Accreditation, reassured UT's stakeholders about UT's strong commitment in providing quality DE in Indonesia. The accreditation process also provided UT's leadership and staff with much needed feedback on past and current achievements and areas for improvement.

The International Organization for Standardization (ISO) is a global network that identifies international standards required by business, government, and society, and develops them in partnership with those economic and service sectors that will put them to use. ISO standards distil international consensus from broad-based stakeholder groups. Input comes from experts closest to the need for the standards. These experts also suggest ways for implementing such standards. ISO standards, although voluntary, are widely respected and accepted by public and private stakeholders on an international scale. Earning ISO certification fosters UT's internal transparency on the use of previously 'self-developed' standardized procedures. The preparation of its obtainment started in 2005, and in March 2006 UT was awarded certification for ISO 9001:2000 for the quality management process of course materials distribution from the Headquarters to Regional Offices. At the time of the writing of this paper, UT is making the necessary preparation for ISO 9001:2000 certifications in the areas of academic development that includes the development of course materials and examination materials, and the management of 11 Regional Offices.

The third external auditor is the National Accreditation Board for Indonesia Higher Education (BAN-PT). This is an accreditation certification that emphasizes in the quality of input, process, and output of education at academic department/study program level. The assessment is done through desk evaluation of the university's portfolio, the Study Program's Self-Evaluation Report and completed accreditation instruments, as well as site visit that includes observations and interviews with representatives of the university's and the faculty's top management, support staff, tutors, and students. The accreditation is granted to individual Study Program within a university, once the respective Study Program has fulfilled the performance indicators set by the Board. The accreditation status is valid for five years and it has to be maintained regularly. At the writing time of this paper, UT is in the process of renewing the accreditation of all its Study Programs.

It is with the three external quality assessors emphasizing in slightly different aspects of UT's management, services, and products, UT is confident to move progressively in its QA system. UT considers the external quality audit is as important as the internal QA process. The most important part of the accreditation process is not in the obtainment of the certificate but more in 
the course of action of getting it. The process of getting each certification and or accreditation has enforced all parties involved to diligently follow the standardized SOP and strictly assure that all the services and products satisfy the main stakeholders.

\section{Lessons Learned and Concluding Remarks}

Several lessons can be learned from UT's endeavors and experiences in QA implementation. First from the beginning, UT was very serious about implementing QA. QA did not just happen over night or piecemeal at UT. In fact, we would be very wrong to give the impression that QA simply 'happened' because we decided to document our work processes and procedures and put policies down in writing - although doing so was clearly an important exercise in self-evaluation and critical reflection! Instead, QA was a well thought out, well-planned, fully integrated operational strategy at the UT, one that encompassed the entire university as an organizational whole and touched upon every process and every unit and every person and every job performed. UT's leadership was rock solid; they invested time and energy necessary to lead and guide the QA process and provide adequate resources to support and sustain QA-related activities. All UT's initiatives were carefully planned and diligently applied with underlying philosophy that all UT's product and services must improve continuously and strive for 'quality.'

QA implementation requires shared responsibility of all UT staff and management. UT's leadership provided clear direction, supervision and resources, and communicated clearly to all stakeholders involved. Challenging and changing prevailing mindsets was essential. QA can only work when everyone is fully of aware and understands what is involved, and that it takes effort and commitment to make 'quality' happen. And it can only happen when all stakeholders from students and frontline staff, to university leadership and government, has input.

A recent trend in QA is that of evolving to become a 'learning organization' (Daft, 2006). As reported by the Commonwealth of Learning (Koul \& Kanwar, 2006) this involves building cultures of 'quality' throughout DE organizations worldwide. Case studies from DE institutions from around the world show ODL's move towards 'quality' provisions and cultures (Koul \& Kanwar, 2006). ODL institutions must learn from each other by communicating and sharing QA benchmarks and best practices.

QA is essential for improving organizational efficiency and effectiveness, increasing public accountability. To meet the challenges of implementing QA, organizations must be ready and willing to adapt, change, and innovate. QA activities must be clear and transparent and, more importantly, they must be achievable and able to meet customer expectations. When QA systems and procedures are clear and activities well defined, only then can ODL institutions meet high quality standards. Internal and external audits must take place so that institutions can track their performance, address any weaknesses, and build upon their successes. ODL institutions must be fully accountable to all stakeholders whether they are government officials, taxpayers, employees, or students. DE institutions that embrace QA principles must constantly strive to improve the quality of their work. To do this, ODL institutions must be open change and innovation, and ready to adapt and engage in global partnerships and competition. Benchmarks and audits must happen regularly and involve staff and management from all levels. QA also requires strong commitment from every stakeholder, from institutional leadership to front line staff, from taxpayers to students. In sum, QA as a management strategy is an effective approach to achieve excellence. 
Problems must be anticipated. QA not only requires adequate funding and ongoing commitment, it requires an 'open mind' to recognize problems. Sustaining and building upon a quality work culture within an organization is a significant challenge. QA should bring about positive changes in organizational structure and culture and lead to measurable results. QA provides ODL leaders with an effective instrument that has helped DE institutions achieve highly recognizable and credible brands. They must also be open to collaboration and competition with other providers, particularly when they have high quality programs.

Effort has only just started at UT. It time to see QA's influences on UT's overall performance. Recent efforts undertaken at UT including linking QA to it human performance indicators. Quality performance is rewarded at UT. Job Manuals help to guide UT's staff members in performing their daily tasks. Writing these QA Job Manuals, however, is more than just documenting daily activities of staff; it involved team building and establishing esprit de corps, improving work systems and procedures, and challenging and changing UT's organizational culture.

Continuous assessment is central to QA and done by individual units to determine what works and what does not work well, and if they are meeting their goals. When units do not perform to a certain benchmark, the university can then undertake remedial actions to help that unit improve their performance.

Finally, only people can make QA happen. UT staff sign agreed-upon work contracts and evaluated throughout the year to monitor their performance. At the end of the year, individual and unit performance is assessed in terms of actual achievement vis-à-vis established benchmarks. If any person or unit is found to fall short of their performance goals, then systems and procedures are examined carefully to ensure they have the skills, tools, and knowledge they need to improve. Performance is directly linked to incentives and compensation, with high performers being rewarded for the effort, innovation and abilities.

\section{References}

BAN-PT (n.d.) National Accreditation Board for Indonesian Higher Education website. Retrieved March 7, 2007 from: http://www.ban-pt.or.id/

Bates, A. W. (2000). Managing technological change: Strategies for college and university leaders. San Francisco: Jossey-Bass.

Belawati, T. (1999). Sejarah pemikiran pendidikan terbuka dan jarak jauh [Development of theoretical framework of open and distance learning]. In T. Belawati (Eds.) Pendidikan terbuka dan jarak jauh [Open and distance education] (pp. 30-44), Jakarta: Universitas Terbuka.

Belawati, T. (2005). The impact of online tutorials on course completion rates and student achievement. Learning, Media and Technology, 30(1), 15-25.

Brennan, J., \& Shah, T. (Eds.). (2000). Managing quality in higher education. Milton Keynes: OECD, SRHE \& Open University Press. 
COL (1997). Planning and Management of Distance Education: Commonwealth of Learning website. London: Commonwealth of Learning and International Extension College.

D'Aprix, R. (1995). Communicating for Change: Connecting the workplace with the marketplace. San Francisco: Josey-Bass.

Daft, R. L. (2006). Organizational Theory and Design, 9th Edition. Mason, OH.: Thomson Southwestern.

Daniel, J. (1999). Open learning and/ or distance education: which one for what purpose? In K. Harry (Ed). Higher education through open and distance learning (p. 292-298). London: Routledge and Commonwealth of Learning.

Daniel, Sir John (1997). Mega-universities, virtual universities and knowledge media: can we have quantity with quality? In P. C. Chew (Ed.) Quality assurance in distance and open learning (p. 3-13), Institut Teknologi Mara, Malaysia: Proceedings of the 11th Annual AAOU Conference.

Deshpande, P. M., \& Mugridge, I. (Eds.) (1994). Quality assurance in higher education. Vancouver: The Commonwealth of Learning.

Garrison, D. R. (1993). Quality and access in distance education: Theoretical considerations. In D. Keegan (Ed.) Theoretical principles of distance education (pp. 9-21). New York: Routledge.

Gosling, D., \& D'Andrea, V. (2001). Quality development: a new concept for higher education. Quality in Higher Education, 7(1), 7-17.

Fozdar, B. I., Kumar, L. S., \& Kannan, S. (2006). A Survey of Study on the Reasons Responsible for Student Dropout from the Bachelor of Science Programme at Indira Gandhi National Open University. International Review of Research in Open and Distance Learning 7(3). Retrieved March 2, 2007 from: http://www.irrodl.org/index.php/irrodl/article/view/291/747

Harman, G. (2000). Quality assurance in higher education. Bangkok: Ministry of University Affairs \& UNESCO PROAP.

Hopkin, A. G., \& Lee, M. B. (2001). Towards improving quality in 'dependent' institutions in a developing context. Quality in Higher Education, 7(3), 217-231.

ICDE (n.d.). International Council for Open and Distance Education website. Retrieved February 28, 2007 from: http://www.icde.org/

ISO (n.d.). International Organization for Standardization website. Retrieved February 28, 2007 from: http://www.iso.org/iso/en/ISOOnline.frontpage

Koul, B. N., \& Kanwar, A, (Eds.) (2006). Perspectives on Distance Education: towards a quality culture. Vancouver, BC.: The Commonwealth of Learning. 
Moore, M. G. (1993). Theory of transactional distance. In D. Keegan (Ed.) Theoretical principles of distance education (pp. 22-38). New York: Routledge.

Peters, O. (1983). Distance teaching and industrial production: a comparative interpretation outline. In D. Sewart, D. Keegan \& B. Holmberg (Eds.) Distance education international perspectives (pp. 95-113). London: Routledge.

Tait, A. (1997). Quality Assurance in Higher Education: Selected case studies. Vancouver, BC.: The Commonwealth of Learning.

UT (2002). Sistem jaminan kualitas Universitas Terbuka (Quality assurance system of Universitas Terbuka). Jakarta: Universitas Terbuka.

Zuhairi, A., Purwanto, A. J., \& Isman, S. M. (2002). Implementing quality assurance system in open and distance learning: the experience of Indonesia's Universitas Terbuka. Paper presented to 16th Annual Conference of Asian Association of Open Universities (AAOU), Seoul, Korea, 5-7 November 2002.

Wikipedia (n.d.) Quality Assurance wiki. Retrieved February 25, 2007 from: http://en.wikipedia.org/wiki/Quality_assurance 